\title{
Editorial
}

\section{To discount or not, that is the question}

\author{
Journal of Revenue and Pricing Management (2013) 12, 205-206. doi:10.1057/rpm.2013.7
}

Because of the Global Financial Crisis, consumers' mindsets have changed to the point that scrutinizing price is even more important. For the majority of consumers, they will never pay full price again, and others' expectations about generous and near-constant discounts have sharpened. Thus, millions of consumers now want to beat the retailer and will happily share details of any savvy purchases in order to demonstrate their commercial expertise. Indeed, consumers probably accrue social status through intelligent purchasing, and if the notion of cutprice shopping once carried any sense of stigma, this has long since been shed. Never before have consumers been better equipped to pinpoint the most competitive deals; in the 2010s, smartphones, price comparison/review sites and group buying services are just some of the tools helping us to locate choice discounts with relative ease. The notion of price has become flexible - it is something to be manipulated, played with and, ultimately, challenged. Although price used to be fixed, it is now very much in flux. Consumers have become accustomed to 'flash' sales, time-limited offers and fluid prices, which can be subject to change from day-today or even hour-to-hour. Price is, as it was, a mere starting point for negotiation. Even when the troubled economic conditions of the early 2010s settle, behaviour learnt during the downturn will not disappear. Simply put, smart shopping makes too much sense to be abandoned. The clamour for discounts will not therefore diminish. Research by the Future Foundation (2012) suggests that more than 85 per cent of consumers say that they are increasingly aware of price - an attitude that very clearly drives the desire for discounts. Growing numbers in all demographic breaks will say that they are now simply unwilling to pay full price for clothes or holidays. Over 70 per cent report that they are prone to delaying the purchase of an item until it is on special offer. Prices in certain sectors more than 50 per cent of shoppers report that they often delay purchases for items such as books and DVDs in the hope of securing a better deal. Such behaviour is more common among younger consumers - but in no group is it undertaken by fewer than a third. Similarly, approximately 50 per cent of consumers say that they enjoy discussing details of good deals they have found with others.

Those in search of savvy deals and bargains can now make use of a wide range of tools and services - many of which can be accessed while out and about. Consumers can use devices such as StripeyLines and Vouchercloud to compare offers and find discounts for nearby leisure venues/retail spaces, respectively. Those consumers can consult specialist advice and product review Websites. Consumers use group buying services to procure serious savings on everything from meals to pedicures to holidays. They employ tools such as Bing's Price Predictor (nz.bing.com/travel) or Nextag's Price Alert (www.nextag.com) to determine the ideal moment at which to buy a product. And these are all services that consumers can expect to become more personalized, more accurate and still more smart. The discounting mindset drives the demand for incidental pricing schemes, where consumers can opt in or out of various service components in order to achieve the offer (and price) that most suits their needs. It is a principle perhaps most well known in the aviation industry (where passengers can, inter alia, choose to pay for hold baggage, priority boarding, 
in-flight meals, travel insurance and so on) but one that is gaining momentum in other sectors too. Therefore, how do you manage the consumers' discounting mindset? The answer is, of course, Revenue Management.

\section{RESEARCH PAPERS}

Noone and colleagues examine price position and performance concluding that optimization models systematically incorporate competitor price information into the derivation of optimal price points. Whereas consideration of competitor pricing at this tactical level is essential to maximizing short-term revenues, the longterm impact of competitive price positioning on revenue performance should not be overlooked, concluding that maintaining a stable relative price position is most important for mid-scale, upscale and economy hotels. Lemke states that forecasting is at the heart of every revenue management system, providing necessary input to capacity control, pricing and overbooking functionalities. For airlines, the key to efficient capacity control is determining the time of when to restrict bookings in a lowerfare class to leave space for later booking highfare customers, with forecasting at the heart of every revenue management system, providing necessary input to capacity control, pricing and overbooking functionalities. The significance of the work is that as revenue management is mainly a professional practice, it unfortunately makes a lot of available knowledge inaccessible to the general research community and as airlines are particularly reluctant to share knowledge of their forecasting methodologies due to commercial sensitivity. This work has given rare insights into the professional practice of a major provider of revenue management software for airline carriers. Bing's work states that in air cargo transportation, freight forwarders need to determine the long-term contract capacity and the capacity purchased from spot market. Bing's article studies how dynamic programming could be utilized to help freight forwarder determine the most cost effective purchase strategy for meeting their capacity needs.
The study uses an optimal booking policy as a set of monotone booking limits. In practice, these booking limits are crucial to applying the models to the complex real-life problems.

Wang considers an assortment optimization problem where a retailer chooses a set of substitutable products to maximize the total expected revenue or profit subject to a capacity constraint. The customer purchase behaviour follows the generalized attraction model, of which the multinomial logit model and the independent demand model are special cases. The authors visualize the efficient assortments and propose a non-recursive polynomial-time algorithm to find the optimal one for the static problem, concluding that the efficient sets significantly reduce the computational complexity in the dynamic assortment management and the optimal policy has a time-threshold structure. Bayourni and colleagues propose a new dynamic pricing approach for the hotel revenue management problem. The approach is based on having 'price multipliers' that vary around ' 1 ' and provide a varying discount/premium over some seasonal reference price. The price multipliers are a function of certain influencing variables (for example, hotel occupancy, time until arrival). There optimization algorithm makes use of a Monte Carlo simulator that simulates all the hotel's processes, such as reservations arrivals, cancellations, duration of stay, no shows, group reservations, seasonality and trend, as faithfully as possible. The transparency of the system, including the knowledge of the variables that affect the pricing, will allay the hotel's concerns regarding the uncertainty of the system's outcome. Hotel managers can start out with fairly tight bands for the allowable premium/discount until they gain enough confidence about the system's performance.

\section{REFERENCES}

Future Foundation. (2012) Discount for ever, http://www futurefoundation.net, accessed 28 March 2013.

Ian Yeoman

Editor

Journal of Revenue and Pricing Management 